\title{
MS33-P20 | SYNTHESIS AND CRYSTAL STRUCTURE OF A NEW BIMETALLIC PLATINUM COMPLEX $\left[\mathrm{PT}_{2}(\mu-\mathrm{H})\left(\mu-\mathrm{PPH}_{2}\right) 2 \mathrm{BR}_{2}\left(\mathrm{PPH}_{3}\right)_{2}\right]$
}

OUIS, Sakina (Université Mentouri Constantine ALGERIA, Constantine, DZA)

Transition metal hydrides play a central role in many homogeneous catalytic reactions (Bertolasi et al., 1993), they are very important in hydrogenetaion or hydroformylation Their characterization is commonly carried out by NMR spectroscopy , X-Ray analysis or neutron diffraction (Ciriano et al., 1978) Hydrides of Pt(II) are the most numerous (Leoni et al . , 1995) of any transition metal hydride group ; In addition to the presence of the hydride ligand the complexes invariably have a coordinated phosphine, the pure complexes are usually both air stable and kinetically inert (Roundhill., 1978) we report here the synthesis and structural analysis of a new hydrodo bridged diplatinum complexe $\left[\mathrm{Pt}_{2}(\mu-\mathrm{H})\left(\mu-\mathrm{PPh}_{2}\right) 2 \mathrm{Br}_{2}\left(\mathrm{PPh}_{3}\right)_{2}\right]$

The title compound is composed of a triangle formed by two platinum atoms and one phosphorus ( $P 2$ ), the coordination sphere of each platinum is completed with a terminal phosphine (P1, P3) and two bromides (Br1, Br2) 